\title{
Malignant Tumors of the Female Genital Tract - a Hospital Based Analysis
}

\section{Jha RJ ${ }^{1}$, Baral $\mathbf{G}^{1}$, Malla $\mathrm{K}^{2}$}

${ }^{1}$ Department of Obstetrics and Gynaecology, Paropakar Maternity and Women's Hospital, ${ }^{2}$ Department of Pathology, Paropkar Maternity and Women's Hospital, Kathmandu

Received: January 22, 2015 ; Accepted: May 15, 2015

Aims: The incidence of cancer and the cancer related deaths are increasing worldwide. There is limited data regarding gynecological cancers in Nepal. This study is conducted to analyze the trends of female genital tract malignancies in Paropakar Maternity and Women's Hospital and compare it with the national/international data.

Methods: This was a retrospective study conducted in Department of Obstetrics/Gynecology and Pathology in Paropakar Maternity Women's Hospital. All female diagnosed with the genital tract malignancies from July 2013 to July 2015 were included in the study.

Results: Among 62 cases, cervical cancer was the commonest (71\%) followed by ovarian cancer (14\%), endometrial cancer $(8 \%)$ and choriocarcinoma (3\%). Majority of women belonged to 50-59 years for each type of tumors. Four-fifth of endometrial, half of the cervical and one-third of ovarian cancers were among grand-multipara. Sixty nine percent of women received treatment with 22 ( 9 cervical, 9 ovarian, 3 endometrial and one of corpus uteri) surgical and 21 primary chemo/ radiotherapy but 19 (31\%) were lost for follow-up. Squamous type of cervical cancer was the commonest (93\%).

Conclusions: Cervical cancer was the commonest genital tract malignancy followed by ovarian cancer, endometrial cancer and choriocarcinoma. For each type of tumors, 50-59 years was the common age group and grand multiparity was seen in half of the women with the cervical cancer. Squamous type of cervical cancer was the commonest variety.

Keywords: genital; malignancy; tumor.

\section{INTRODUCTION}

Cancer is the leading cause of the mortality in developed countries while it ranks second in developing country. ${ }^{1}$ More than $60 \%$ of world's total new annual cases have been found in Asia, Africa, Central and South America. Cancer deaths in these region accounts for $70 \%$ of world's cancer related deaths. ${ }^{2}$ Cancers of breast, lung, stomach, colon, rectum and cervix uteri are most common cancers in female worldwide while in Nepal cancers of the cervix, breast, lung and ovaries are the commonest ones. ${ }^{3}$ Gynecological cancers are public health problem in all the countries. The cancer registry system in Nepal has not been very effective and is not a population based registry system. Genital tract malignancies have been found to be increasing every year in our country as seen in the

\section{CORRESPONDENCE}

Dr Rijuta Joshi Jha

Department of Obstetrics and Gynaecology,

Paropakar Maternity and Women's Hospital, Thapathali, Nepal

Email: dr.rijutajoshijha@yahoo.com

Phone: +977-9851151830 hospital based reports (WHO supported new cancer registry system). ${ }^{1,3}$ There have been a lot of recent advancements in the cancer treatment throughout the globe but Nepal is still struggling to provide even conventional modalities of cancer treatments to the general public due to the poor infrastructure of the health care system, socio-economic and political conditions. ${ }^{3}$ This study is an attempt to add to the much needed information about the genital tract malignancies detection and its management in a tertiary hospital of the country. In the last two years there were $0.13 \%$ of genital tract malignancies among the total gynecological cases admitted excluding Persistent Gestational Trophoblastic Tumor (PGTT) who received chemotherapy at this hospital. ${ }^{4,5}$

\section{METHODS}

This was a hospital based retrospective crosssectional study conducted in the Departments of Obstetrics and Gynecology and Pathology for two years from July 2013 to July 2015. Approval for the study was taken from the ethical board of the hospital. The case notes of the patients with the female genital tract malignancy were retrieved from the medical 
statistics department and data was also taken from the cancer registry of the hospital. The data extracted were socio-demographic information like age, parity and marital status; clinical symptoms, stage, site, histopathology type of cancer and the definitive management. Data were entered into Microsoft Excel workbook 2007 and exported to the SPSS 16 for the descriptive analysis. Tables and graphs were made to project the results. WHO classification was used for the histopathology.

\section{RESULTS}

Out of 62 cases of female genital tract malignancies in two years majority $44(70.96 \%)$ of them were from out of KathmanduValley. Fifty-eight percent ie 36 women were only involved in household works while agriculture was the main source of income in 12 (19.35\%)of the cases. All of them were married and $39(62.9 \%)$ had their first childbirth before 20 years. Majority of them i.e., 35 (56\%) and $55(88.7 \%)$ women did not smoke or chew pan/tobacco respectively. Clinical examination aided by radiological investigation was the main mode of diagnosis, which was confirmed by the histopathological examination of the biopsy/tissue specimen. Most of the patients diagnosed with the early stage of malignancies underwent surgical treatment and patients who required chemotheraphy/ radiotheraphy were referred to Oncology Department in Bir Hospital or Bhaktapur Cancer Hospital according to the patients' convenience. According to the WHO classification, Cancer of the cervix was the most common:44 (71\%) followed by the carcinoma of the ovary: $9(14 \%)$, carcinoma of endometrium:5 (8\%) and choriocarcinoma: 2 (3\%) \{Figure 1$\}$.

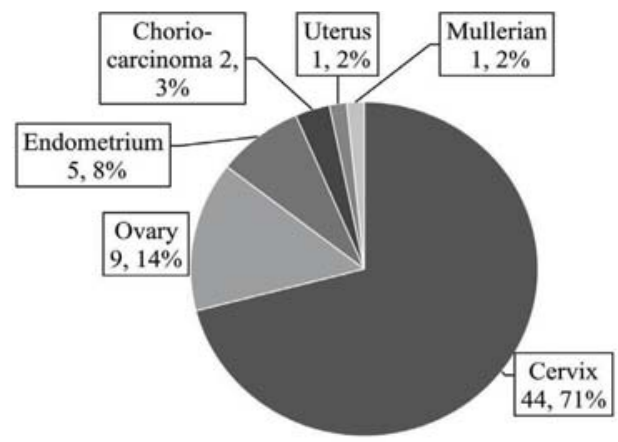

Figure 1. Frequency distribution of genital tract malignancy
Table 1. Parity wise distribution of genital tract malignancy $(\mathrm{n}=60)$.

\begin{tabular}{|lllll|}
\hline Parity & Cervix & Ovary & $\begin{array}{l}\text { Endo } \\
\text { metrium }\end{array}$ & $\begin{array}{l}\text { Chorio } \\
\text { carcinoma }\end{array}$ \\
\hline 0 & 0 & 2 & 0 & 0 \\
1 & 0 & 1 & 0 & 1 \\
2 & 10 & 2 & 1 & 0 \\
3 & 12 & 1 & 0 & 0 \\
$\geq 4$ & 22 & 3 & 4 & 1 \\
Total & 44 & 9 & 5 & 2 \\
\hline
\end{tabular}

\section{Age distribution}

50-59 years was the common peak age group for each type of tumors. Two-third cases of carcinoma of cervix were in 40-60 years age group with peak at 50-59 ie in 17 women (39\%) followed by 40-49 ie in 11 women $(25 \%)$ and 60-69 ie in seven women (16\%) with only five women $(9 \%)$ under 40 years. One-third each fell under 40 years and in 50-59 years age group for the ovarian cancer. All four cases out of five endometrial cancer were in age 50-59 group.

Majority of the women i.e 39 (62.9\%) had their first childbirth in $<20$ years. Among the women with cervical cancer, $31(70 \%)$ had their first childbirth in $<20$ years.

\section{Parity}

Four-fifth of endometrial, half of the cervical and one-third of ovarian cancers were among grandmultipara $(\geq 4)$.

\section{Staging}

Cancers were diagnosed and staged by clinical, laboratory, imaging and surgical means. Majority of the women ie 26 were in stage I, 19 in stage II, 12 in stage III and three in stage IV. The stage wise distribution of cervical cancer was 20 in stage I, 14 in stage II, eight in stage III and two in stage IV.There were $77 \%$ surgically operable tumors- 15 small (IA and IB1) and 19 big (IB2, IIA and IIB) (figure 3). Ovarian cancers were in one in stage I, four in stage II, three in stage III and one in stage IV. Four cases of endometrial carcinoma were in stage I and one in stage II. In case of chorio-carcinoma, one each was in stage I and III. 


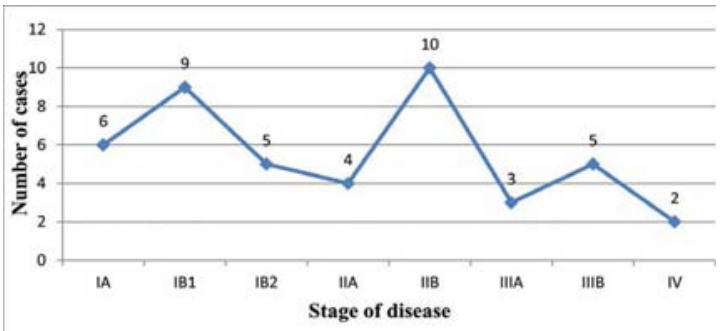

Figure 3. Distribution of cervical cancer by stage $(n=44)$

\section{Histopathology}

Squamous and adenomatous types of cervical cancer were $93 \%$ and $7 \%$ respectively with $93 \%$ histological differentiation (Figure 4).

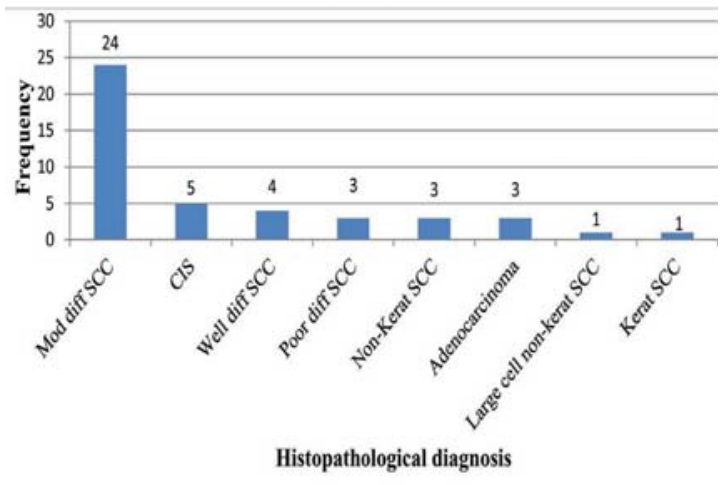

Figure 4. Histopathological diagnosis of cervical cancer $(n=44)$

Clinical examination was the mainstay of the diagnosis in the majority of the carcinoma of the cervix, which was confirmed by histopathology. In cases of malignant ovarian tumor, there were four cases of serous adenocarcinoma, and one each for endometroid, mucinous and secondary tumor of ovary; one each for immature cystic teratoma (Ia,G3 ) and adult granulosa cell tumor in germ cell origin. Out of five cases of endometrial carcinoma, there were two cases of endometroid two adenosquamous and a case of smooth muscle cell tumor of uncertain malignant potential (STUMP) was seen in corpus uteri.

\section{Treatment}

Out of 62 cases, $69 \%$ received treatment with 22 (9 cervical, 9 ovarian, 3 endometrial and one of corpus uteri) surgical and 21 primary chemo/radiotherapy but 19 (31\%) did not follow-up for the treatment. As for the women with choriocarcinoma, both of them received chemotherapy. Cases who received chemotherapy for persistent gestational trophoblastic tumor (PGTT) were not included in this review.

\section{DISCUSSION}

In this study, cervical cancer was found to be the most common genital tract malignancy followed by the ovarian cancer which is similar to the other studies done in Nepal, India, Pakistan and Nigeria. ${ }^{6-9}$ In a study done by Pokharel et al, ${ }^{9}$ carcinoma of the endometrium and choriocarcinoma were the third and fourth common genital tract malignancy like in this study. Vulval and vaginal cancers were found to be around $2-3 \%$ in other studies while the least common malignancy was of that of the fallopian tube $(<1 \%) .{ }^{6,9}$ However, in this study there were no cases of vulval, vaginal or fallopian tube cancer similar to the findings in a comparative study done by Rahaman and colleagues and Narula and colleagues. ${ }^{8,10}$ In a study done in Nigeria, similar to this study, cervical cancer was the commonest followed by the ovarian cancer and the least common was the cancer of corpus uteri and that of vulva while there were no cases of vaginal carcinoma or fallopian tube carcinoma. ${ }^{11}$

\section{Cervical cancer}

Annually, over 500,000 new cases of cervical cancer are diagnosed worldwide while in Nepal it is 2,332 women every year, making it the commonest cancer among women in Nepal. ${ }^{12-14}$ Although many primary, secondary preventive measures and treatable approaches have been developed to prevent and treat the cervical cancer in the early stages, more than onethird of women diagnosed with cervical cancer die due to it. ${ }^{13}$ It is the second most common cause of cancerrelated death among women worldwide and 50\% mortality rate is seen in Asia while in Nepal 1,367 women die from the disease every year. ${ }^{12,13}$ Late stage at diagnosis is one of the causes for their lowered survival rates. The lack of awareness regarding HPV infection, screening and availability of vaccine for its prevention in the general populations and health professionals in a large scale as well as other cultural and social issues has led to the presentation of cervical cancer in the advanced stages in the developing countries like ours. ${ }^{13,15-17}$ Besides the mortality, invasive cervical cancers have a huge impact in sexual life (dyspareunia and reduced autonomic response), reproductive and bladder function (voiding problems). Significant morbidities resulting from the chronic pain (due to bony invasions), renal failure (due to ureteric involvement), fistula and discharge are also common. ${ }^{17}$ 
Like in other studies done in Nepal, in this study also maximum women with carcinoma cervix were found to be in their $5^{\text {th }}$ and $6^{\text {th }}$ decade. ${ }^{6,15,18}$ Increasing incidence of cervical cancer was seen with the increasing parity similar to the study done in Nigeria by Okeke et al. ${ }^{11}$ In this study, in the women with the carcinoma of cervix, $70 \%$ had their first child birth in $<20$ years. This is supported by the fact that early age at first sexual intercourse, early age at first marriage and early age at first pregnancy are linked to higher incidence of HPV infection and cervical carcinoma in women of developing countries. ${ }^{19}$ In this study, $45 \%$ of the cervical carcinoma was of stage IIb and more. This is less compared to the study done in the two big referral cancer hospitals of Nepal where $80.9 \%$ of the patients had late diagnosis (stage $\geq \mathrm{IIb}$ ) during the study.$^{15}$ In another study done in BPKIHS, similar higher number of advanced cases of the cervical carcinoma was found. ${ }^{9}$ The late presentation of the cervical cancer in their study could be due to the reason that women had to make an average of five consultations at nearly three different health facilities before being referred to the diagnostic center. PMWH is not a referral cancer hospital so the advanced cases of cervical cancer were not seen in large numbers. Very small percentage of women $(n=20,9.25 \%)$ with cervical cancer underwent surgery and majority ( $\mathrm{n}=196,90.7 \%)$ underwent chemotherapy/ radiotherapy in the study done by Pokharel et $\mathrm{al}^{9}$ in BPKIHS whereas this study shows $n=9,20.5 \%$ of surgical treatment. Thirty-one percent of women with the cervical cancer were lost to follow up in this study resulting in the missed surgical opportunity. This may be due to lack of awareness about the disease itself, social and economic constraints as the majority of the women in the study were from rural areas outside of Kathmandu and could be due to their financial dependence on others. On histopathological examination, squamous cell carcinoma was the commonest type of cervical cancer similar to the other studies. ${ }^{6-8,17}$

\section{Ovarian cancer}

Despite of the improved surgical techniques and novel chemotherapeutic agents, ovarian cancer still pose a great challenge due to the late presentation in advanced stages (because of their location) and accounts for a disproportionate number of fatal cancers which has not improved significantly over the past three decades..$^{7,20,21}$ The percentage of women with the ovarian malignancy $(n=9,14 \%)$ in this study is similar to the findings of the study done by Pokharel et $\mathrm{al}^{9}$ in Nepal $(\mathrm{n}=54,17 \%)$. However, it is less compared to the studies done in India and Nigeria where it ranged from $21-30 \%{ }^{10,11}$ In this study, the majority of women with the ovarian cancer were in 50-59 years corresponding to other studies where it has been found to be more common in women of 40 to 65 years. ${ }^{7,10}$ In some other studies, the mean age of females with ovarian carcinoma ranged from $37 \pm 14.66$ to 44.7 years, which is lower than in this study. $6,8,9$ Majority of the patients with the ovarian cancer i.e. 5 $(55.5 \%)$, had parity of two or less similar to the study done by Rahaman et al ${ }^{8}$ Multiparity has been related with a significant decrease in the risk of development of ovarian cancer. ${ }^{22}$ Serous adenocarcinoma was the commonest ovarian malignancy and found in $44.4 \%$ cases, similar to other studies. ${ }^{6,723}$ Majority of the ovarian carcinoma were of early stage (and initially assumed to be the benign ovarian cyst) with a single case of stage IV. This finding is in contrast to its usual late presentation. This may be due to the easy access and increasing use of ultrasound leading to its early detection.

\section{Endometrial cancer and choriocarcinoma}

Carcinoma of the endometrium in this study was less ( $n=5,5 \%$ ) compared to the findings of Pokharel et $\mathrm{al}^{9}$ $(n=32,10 \%)$ but slightly higher than the study done by Dhakal et $\mathrm{al}^{6}(\mathrm{n}=32,2 \%)$ which is in contrast to the findings of the western countries where endometrial carcinoma is high $(35 \%$ of all gynecological malignancies). This low incidence of endometrial cancer could be due to the low incidence of obesity, hypertension, diabetes mellitus, breast cancer and family history of breast/ovarian cancer in our context compared to the West. ${ }^{18}$ The mean age of endometrial cancer ranged from 52 to 57 in other studies. ${ }^{6,79}$ Likewise, in this study majority of the women with endometrial cancer were in 50-59 years. Endometrioid variety was the commonest in this study, which is correlating with the findings in other studies. ${ }^{6,8}$ Choriocarcinoma was seen in the second to the fifth decades in other studies similar to this study. ${ }^{79,10}$ Like in this study, the incidence of choriocarcinoma was less $(0.33-4.3 \%)$ in other studies. ${ }^{6,8,11,24,25}$ This is in contrast to the finding of study done by Mohammad et $\mathrm{al}^{7}$ in Nigeria where choriocarcinoma was the commonest cancer of corpus uteri. 


\section{CONCLUSIONS}

Among female genital tract malignancies, cervical cancer was the most common followed by the ovarian malignancy, endometrial cancer and choriocarcinoma respectively. The common age group for all the malignancies was 50-59 years. Sixty-nine percent received some form of primary treatment including surgical and or chemo/radiotherapy and 31\% were lost for follow-up. Squamous type of cervical cancer was the commonest variety.

\section{DISCLOSURE}

The authors report no conflicts of interest in this work. No violation of human rights and safety.

Funding: Nil

\section{REFERENCES}

1. The Global Burden of Disease: 2004 Update. Geneva: World Health Organization; 2008.

2. World Cancer Report. Geneva: World Health Organization; 2015 .

3. Subedi KS, Sharma P.Cancer treatment in Nepal: a historical background, development of treatment facilities, epidemiology and challenges for prevention and control of cancer. Austral - Asian J Cancer. 2012;11(3):205-11.

4. Paropakar Maternity and Women's Hospital. SMARIKA Kathmandu.2014;55:55.

5. Paropakar Maternity and Women's Hospital. SMARIKA. Kathmandu.2015;56:81.

6. Dhakal HP, Pradhan M. Histological patterns of gynecological cancers. J Nepal Med Assoc. 2009;48(176):301-5

7. Mohammed A, Ahmed SA, Oluwole O, Avidime O. Malignan tumors of the female genital tract in Zaria, Nigeria: analysis of 513 cases. Annl Afr Med. 2006;5(2):93-6.

8. Rahman MA, Siddika ST, Mazid MA. Gynaecological cancers in surgical specimens -a hospital based analysis. Medicine Today. 2014;78(26):78-82.

9. Pokharel HP, Basnet N, Uprety D, Banerjee B, Sinha A, Pokharel PK. Malignancies of the female genital tract from general gynecological services: five years review at BPKIHS. NJOG. 2007;2(1):35-8

10. Narula R, Arya A, Narula K, Agrawal K, Agrawal A, Singh S Overview of benign and malignant tumours of female genital tract. J App Pharm Sci. 2013;3(01):140-9.

11. Okeke TC, Onah N, Ikeako LC, Ezenyeaku C. The frequency and pattern of female genital tract malignancies at the University of Nigeria Teaching Hospital, Enugu, Nigeria. Ann Med Health Sci Res. 2013;3:345-8

12. Human papilloma virus and related cancers, fact sheet 2014 Nepal: ICO Information Centre on HPV and Cancer; 2014 Dec.

13. Daniyal M, Akhtar N, Ahmad S, Fatima U, Akram M, Asif HM. Update knowledge on cervical cancer incidence and prevalence in Asia.Asian Pac J Cancer Prev. 2015;16(9):361720 .
14. Gilbert DC. Human papilloma virus and cancer of the cervix: a challenge facing Nepal. Kath Univ Med J.2006;15:396-7.

15. Gyawali D, Pariyar J, Onta SR. Factors associated with late diagnosis of cervical cancer in Nepal. Asian Pac J Cancer Prev. 2013;14(7):4373-7.

16. Kanavos P.The rising burden of cancer in the developing world. Annl Oncol. 2006;17(8):15-23.

17. Hannermann M, Bailey J, Murdoch J. Recent advances in the surgical management of cervical cancer. In: Bonnar J, Dunlop W, editors. Recent advances in obstetrics and gynecology 23. London: The Royal Society of Medicine Press Ltd; 2005. p.231-42.

18. Mohammad A, Makaju R. Retrospective histopathological analysis of various neoplasm of the female reproductive system (FRS) seen at the Kathmandu University Teaching Hospital, (KUTH) Dhulikhel, Nepal. Kath Univ Med J. 2006;4(1):48-53.

19. Bhusal CL, Manandhar S, Singh M, Shah A, Neupane S, Karmacharya D et al. Evidence of HPV subtypes linked with cervical cancer in Nepal. WHO South-East Asia J Public Health 2012;1(4):441-5.

20. Farooq F, Noman D, Humayun N, Naveed N, Haider A.Demographic differentials and histopathological patterns of ovarian masses. Biomedica. 2015; 31(2):118-23.

21. Rosenthal A, Jacobs I. Overview of ovarian cancer screening. In: Bonnar J, Dunlop W, editors. Recent advances in obstetrics and gynaecology 23. London:The Royal Society of Medicine Press Ltd; 2005. p.243-59.

22. Modan B, Hartge P, Yechezkel GH, Chetrit A, Lubin F, Beller $\mathrm{U}$ et al. Parity, oral contraceptives and the risks of ovaian cancer among the carriers and non-carriers of BRCAland BRCA2 mutation. N Eng J Med. 2001;345(4):235-40.

23. Ullah E, Lail RA, Taj N, Alam MI. Malignant and benign lesions of female genital tract-an experience at a tertiary care hospital in Bahawalpur-Pakistan. Biomedica. 2012;28:14952.

24. Thapa K, Shrestha M, Sharma S, Pandey S. Trends of complete hydatidiform mole. J Nepal Med Assoc. 2010;49(177):10-3.

25. Koirala A, Khatiwada P, Giri A, Kandel P, Regmi M, Upreti D. The demographics of molar pregnancies in BPKIHS. Kathmandu Univ Med J. 2011;36(4):298-300. 